\title{
TREATMENT IN GENERAL PRACTICE
}

This article is one of a series on the management of some of the rheumatic diseases met with in general practice.

\section{SPA TREATMENT IN GENERAL PRACTICE}

BY

GEOFFREY HOLMES, M.B., B.Ch.

Spa treatment may be defined as a regime for the cure or amelioration of certain diseases which are amenable to treatment by physical methods. An essential feature is the taking of mineral waters internally, as well as their external application in the form of baths and douches. It also includes as auxiliary methods the use of massage and mechano-therapeutics and the whole range of electrical treatments. Finally, as further aids, come change of climate and surroundings, freedom from business worries, and the general amenities that are to be found at all well-equipped spas. The sum total of these factors makes up spa treatment.

The first question that may arise from the foregoing definition is whether the same results could not be obtained by the use of plain tap-water as by the use of spa waters. All water applied in accordance with the principles of medical hydrology has therapeutic value, and as immersion baths, at varying depths and temperatures, and for varying periods of time, or as douche massage and sprays at graduated temperatures and pressures, it can profoundly influence metabolism. The fact that balneological principles are the same whatever waters are used accounts in part for the considerable overlap in the list of ailments which spas in common claim to treat successfully, even though their waters differ as greatly as the thermal radio-active waters of Bath and Buxton, the sulphur waters of Harrogate, Strathpeffer, and Llandrindod, the brine baths of Droitwich, and the saline waters of Cheltenham and Leamington. It was the discovery that the natural waters in these localities possessed distinctive medicinal properties over and above those of plain water that led to the establishment of spas around their sources, and it need only be added here of spa waters in general that their special chemical and physical constitution determines their tonic or alterative influence, or makes them purgative or diuretic, and thus eliminative through bowels, kidneys, or skin.

The next point in the definition of spa treatment that calls for explanation is the use of the word regime. A properly planned "cure" includes consideration of the patient's diet and habits, and apportioning of his day for amusement, rest, or exercise, as well as the prescription of physical treatment. In the environment of a spa this can be done in a manner which is impossible at home for the busy man or woman, and would prove irksome even for people of comparative leisure. As regards the actual " treatments," it must be stressed that it is only by a carefully regulated routine that the desired cumulative effects can be obtained; the haphazard use of waters internally and of physical treatments externally is quite as likely to do harm as good.

\section{Cases Suitable for Spa Treatment}

Spa treatment has no place in the treatment of acute illness, and patients who are unfit for conveyance to and from the baths and other therapeutic departments should not be sent to spas; on the other hand, it is of the greatest value as a preventive measure, and this is being realized by increasing numbers of people who have no time for relaxation or attention to health when at home. While its widest field is in the treatment of chronic diseases, cases should be sent as early as possible and before irreparable structural changes have occurred; further mention of this will be made when discussing the best time for visiting a spa.

The following classification of the main types of spa treatment in terms of metabolism, as suggested by Edgecombe, is offered as a useful guide to the conditions for which such treatment is indicated.

1. The Anabolic Type.-The aim is to build up the system by promoting assimilation and by avoidance of measures likely to stimulate excessive output. Examples of conditions suitable for this type of treatment are: convalescence from acute illness ; general debility, such as is produced by many tropical diseases; atrophic arthritis; and functional nervous disorders.

2. The Katabolic Type.-The aim is to stimulate the metabolic processes to such an extent that the excretion of waste products exceeds the amount of tissue regeneration. This type of treatment is indicated for the obese, the over-fed, and the under-exercised.

3. The Metabolic or Intermediate Type.-This is a form of treatment for cases in which metabolism is not necessarily either excessive or deficient, but requires " alterative" treatment, as in the gouty, cases of sluggish liver function and dyspepsia, the hyperpietic, and the majority of cases of rheumatism and fibrositis. In this category may be placed the tired business or professional man suffering from the effects of worry and overwork.

Before the " cure" is begun it should be decided just what form of treatment under the above classification is indicated, and it should be left to the spa physician, in view of his knowledge of the local waters and treatments available, to decide how the desired results can best be obtained.

\section{Selection of a Spa}

The general practitioner should be prepared to give advice on the selection of a health resort. So far as possible it is advisable to allow the patient to follow his own choice, as some people have a rooted objection to being "sent" anywhere, but if the home doctor disagrees with this choice he should be able to give reasons based on climatology, the nature of the waters and treatments, and the accommodation and general amenities provided. The distance from home calls for consideration. In some cases it is a distinct advantage for the patient to be moved well away from home, relatives, and friends ; in other cases-as, for example, when the patient is elderly, feeble, or has much pain on movement-an unnecessarily long journey should be avoided. For the elderly patient in particular, unless accompanied by a friend or relative, the onset of sudden illness far from home may cause much anxiety and expense.

As guides to the selection of spas, circulars and advertisements contain much useful information, but they reveal a not unnatural tendency for each spa to claim to deal successfully with all the ailments amenable to treatment by baths and waters. There is now available a reliable and impartial guide in the Official Handbook of the British Health Resorts Association, ${ }^{1}$ while for the practitioner requiring fuller information and medical indications Hydrotherapy and Climatotherapy, ${ }^{2}$ by Dr. Matthew B. Ray, contains all essential details. There 
is also a chapter on "The Choice of a Spa and Climate" in Dr. W. S. C. Copeman's book, The Treatment of Rheumatism in General Practice. ${ }^{3}$

\section{When to Visit a Spa}

This also is a matter requiring the advice of the family doctor, and on this point generalization is difficult. The preceding paragraphs offer a rough guide as to the kind of case for which such a visit might prove beneficial, but the stage of an illness at which a patient should be sent to a spa calls for judgement in each instance. When the acute phase of an illness is over, if the patient is not continuing to make progress or is losing ground on medicinal or such other treatment as is available at home, a visit to a spa may do much to facilitate recovery.

A few common conditions may be given as examples. Colds or " influenzal " attacks are not infrequently followed by a continuation of aches and pains, or the onset of general fibrositis after the febrile period is over ; tonsillitis may be followed by pain and swelling in the joints. If these conditions do not respond to salicylates or other drug treatments, or to massage and electrotherapy at home, spa treatment may artest a drift towards a general rheumatic or arthritic condition. Patients who have had rheumatic fever should not be sent for spa treatment until after at least three months of the onset of the illness, even in the absence of cardiac lesions, as the reaction caused by bath treatment is apt to precipitate a relapse to the febrile condition if given too soon. On the other hand, fibrositis or arthritis following on rheumatic fever after the febrile stage and the necessary period of rest usually responds well to balneotherapy.

There is often a very trying lag in the recovery of cases of sciatica. When the acute stage, which makes rest in bed imperative, is over peat baths or hot saline baths with undercurrent douching may be well tolerated, even before the patient can bear massage. Arthritis showing itself during or shortly after the menopause can usually be arrested by spa treatment, and these cases should be sent before structural changes are advanced.

The results of overfeeding and lack of exercise which manifest themselves in many patients towards the end of the winter months can usually be removed by a visit to a spa for a " spring cleaning." The overtired business man, especially with incipient hyperpiesis, may be well advised to take his annual holiday at a spa. Many more instances might be given, but the foregoing serve to illustrate the importance of choosing the appropriate time in the course of an illness for recommending spa treatment.

The time of year for a visit to a spa also calls for consideration. The British spas are open all the year round, but it is much more pleasant to visit a spa when the weather is reasonably warm and fine, and when such additional amenities as spas provide during their season can be enjoyed. The condition of the patient must, of course, be the first criterion, and while it is safer not to send elderly patients, . especially those subject to bronchitis, for spa treatment between the beginning of December and the end of April, most other cases can take their cure at any time of the year provided they get accommodation near the bathing establishments during the cold months. It is noteworthy that patients coming straight home from the Tropics seem to stand our winter climate well, and find it bracing.

\section{Preliminaries to Spa Treatment}

Accurate diagnosis is as essential to success in spa treatment as in other forms of treatment, and it is the obvious duty of the spa practitioner to give each patient consulting him a careful general physical examination before prescribing. It is most desirable that the general practitioner should give his patient a thorough examination shortly before he leaves home and let him have, or send in advance, for the information of the spa doctor, a report containing such details of the case as the patient would expect to take to any other specialist or consultant.

It is always advisable that there should not be an unduly long interval between independent examinations by any two doctors, as this minimizes the chance of any new condition manifesting itself, thus leading to divergent findings and opinions. In his examination the spa doctor may note abdominal scars, and it gives the patient confidence if he finds that the doctor knows whether the operations have been for the removal of abdominal or pelvic organs, rather than if he has to make inquiries concerning them. It is also useful to know what treatment, if any, has been given during the few weeks before the patient leaves home; whether he habitually uses aperients or sedatives ; and, particularly, if he has any food or drug idiosyncrasies.

In ailments due to or associated with septic foci it is desirable that these should be dealt with before the patient leaves home, partly on grounds of economy, partly because of the additional inconvenience of having such things as dental extractions done away from home, and finally because the spa treatment is much more likely to prove beneficial if sources of toxaemia can be removed beforehand.

The larger spas are equipped for all forms of investigation, and it may be convenient for the general practitioner whose patients are not within easy reach of a pathologist or radiologist to send them to a spa for general investigation as well as treatment. Although it is only in the minority of cases that special pathological or biochemical investigations are required, it will enable the patient to begin treatment without delay and to continue it without interruption if these examinations can be made at home. In most cases a note from his own doctor tends to put the patient at ease when seeing a stranger, and, incidentally, the presentation of such a note calls for the courtesy of a report when he returns home.

\section{Cost of Spa Treatment}

When the general practitioner suggests spa treatment he will probably be asked what it will cost, for there is a prevalent but quite erroneous idea that spa treatment is provided mainly for the well-to-do. This may have arisen from the fact that in pre-war days a visit to a spa was often regarded more as part of the social round than as a serious form of treatment. Nowadays the spa clientele is composed almost entirely of people genuinely in need of treatment, and the malade imaginaire is seen at the spas no more often than elsewhere. The main cost of a visit to a spa, as to other seasonal resorts, is that of board and lodging. This may be anything from two pounds a week in the smaller lodgings up to the usual charges of luxury hotels. The actual treatments may be said to cost from one to two pounds a week, but information on these and similar points is readily supplied on request to the local spa manager. The average duration of a "cure" is three weeks, this being the time that is usually found necessary to produce the desired effect by a course of baths and waters. It is rarely worth while to take baths and waters for less than a fortnight, and few patients can take spa treatment for more than a month without a break. In very chronic cases, or for patients so delicate that they can only take treatment two or three times weekly, a longer stay may be desirable, but that does not apply to the average case.

It may be mentioned here that if the patient will notify the spa doctor he is advised to consult of the date and hour of his arrival that will usually enable him to obtain 
his prescription on the same day, so that he may begin treatment without delay. For the insured classes the British Spas Federation, with the co-operation of the Spa Group of the British Medical Association, has offered spa treatment to the members of those approved societies which are prepared to give it as an additional benefit, and the same terms are offered to their families. Finally, the spa hospitals are available for those who are uninsured or cannot afford the treatment as private patients. Terms of admission are supplied on application to the secretaries of the various hospitals.

REFERENCES

'British Health Resorts, Spa, Seaside, Inland. The Official Handbook of the British Health Resorts Association. J. and A. Churchill. (1s.)

Hydrotherapy and Climatotherapy. By Matthew B. Ray, M.D. Edward Arnold and Co. (12s. 6d.)

- The Treatment of Rheumatism in General Practice. By W. S. C. Copeman, M.D. Edward Arnold and Co. (9s.)

\section{LUNCHEON TO VISITING AUSTRALIAN MEMBERS}

An informal luncheon, given by the chief officers of the British Medical Association, was held at Grosvenor House, London, on June 24th, for the purpose of meeting and welcoming the Right Hon. Earle Page, F.R.A.C.S., Minister of Commerce and Deputy Prime Minister of Australia, and a number of Australian members of the Association who had already arrived in England in connexion with the Oxford Meeting. The guests included the following:

Dr. J. G. Hunter (honorary secretary, Federal Council of the British Medical Association in Australia and the New South Wales Branch), Mr. T. B. Edye, Dr. W. Keith Inglis (New South Wales Branch), Dr. G. Newman Morris, Dr. L. J. C. Mitchell, Dr. D. J. Thomas (Victorian Branch), Dr. J: V. J. Duhig (Queensland Branch), Mr. F. A. Hadley (Western Australian Branch), Dr. R. H. Strong (a host at Melbourne), Professor J. C. Windeyer (Sydney), and Dr. A. E. Colvin (member of the Legislative Council of Australia). Mrs. Earle Page was also present, and several of the other guests were accompanied by ladies.

\section{Welcome to the Guests}

Dr. E. Kaye Le Fleming, Chairman of Council, presided and welcomed the guests, introducing them individually to their English colleagues. Those who visited Australia last year, he said, had delightful recollections of the entertainment afforded them, and desired at the earliest opportunity to renew the acquaintance of their Australian friends. He regretted some absentees. It had been hoped to have present Mr. Robert Menzies, Attorney-General for the Commonwealth and Minister of Industry, but he was unable to come, and Sir Isaac Isaacs, late GovernorGeneral, had had to telephone at the last moment to say how sorry he was to have been prevented. Dr. Le Fleming went on to say that his own memory, and probably that of many others present, went back to the banquet at Melbourne last year, when Mr. Page Earle had proposed the toast "The British Medical Association." Later he had almost insisted that the visitors should go to Canberra. A number did so, and were most grateful for the experience. Canberra, the great administrative centre of Australia, had fired their imaginations to such an extent that they could visualize it as a mighty influence gathering up and welding together the States of the Commonwealth. On such occasions as the present it was always a pleasure to welcome members of the medical profession who had reached places of influence in public affairs. Therefore they graatly honoured Mr. Earle Page as a member who had brought much credit to the profession and much benefit to Australia. Those who had visited Australia had followed with keen and not unsympathetic interest some of the problems which Mr. Earle Page had come to England to try to solve, and they wished him every success in his negotiations and a safe and happy return to his native land. Congratulations were due to $\mathrm{Mr}$.
Earle Page and his countrymen on four knighthoods bestowed on medical men in Australia and New Zealand, as announced in the Birthday Honours List on the previous day (Journal, June 27th, p. 1314). He called upon those of the Homeland to rise and drink the health of their guests and of the great Commonwealth from which they came.

\section{The Acting Prime Minister's Reply}

Mr. EARLE PAGE, in responding, said that members of the profession in Australia were most grateful to the British Medical Association for paying a visit to that country; the result of the Melbourne meeting of 1935 had proved beneficial to Australia in many ways, notably in stimulating an interest in research. The visit of the Association had put the medical profession right in the front of the picture, and perhaps the fact that out of nine new oversea knights four were Australian or New Zealand doctors might be taken as an indication of what the Government at the Antipodes thought about the medical profession. At the same time, members of the profession in Australia fully shared the gratification of their home colleagues at the viscountcy conferred upon Lord Dawson of Penn, who was not only a great doctor and an able exponent of the standpoint of the profession, but a man whose vision and grasp of social affairs had impressed the Empire at large.

Medical men to-day (Mr. Earle Page continued) had the opportunity of exercising a more direct influence on world affairs than they had ever been able to do in the past. It was becoming more and more evident that the immediate effect of policies of economic nationalism was to bring about a definite falling off in the nutrition, and therefore in the health, of the peoples, especially of Europe. It was for the medical profession, not of one but of all countries, to give a lead in this matter and to create a public opinion which would ensure that some of the root causes of malnutrition were abolished. $\mathrm{He}$ recalled with pride that it was Australia which had taken the initiative in this matter at Geneva, where the question was faced both from the health and from the economic point of view. It was pointed out there that the countries of Europe were concentrating on wheat and other staples to the neglect of diet rich in vitaminsbutter, eggs, fresh fruit and vegetables, and so on. If the agriculturists of Europe could be persuaded to produce such foods in the amount necessary for the establishment of properly balanced diet for the European peoples, a way out would be found from many present difficulties. But this fairly obvious course would never be taken unless the medical profession persistently pointed the way. It could never be suggested against the medical profession that it was grinding any axe of its own, because by helping to raise the physical standard and the common health it was helping to diminish the means of livelihood of its members. He hoped that the British Medical Association would follow up its admirable work on nutrition with a lead on these wider aspects of the matter.

In conclusion, Mr. Earle Page said how much he and his fellow guests had appreciated the kindness extended to them. The visit of the Association to Australia would be long remembered; its effects so far as medical education and research were concerned would be permanent. $\mathrm{He}$ hoped that before very long, with faster travel services, it might be possible again to welcome members of the Association for a meeting in Australia, the journey thereto growing gradually less formidable.

Among others present who joined in welcoming the Australian colleagues were:

Sir E. Farquhar Buzzard, Bt., President E'ect of the Association: Sir Holburt Waring, late President, Royal College of Surgeons ; Sir Ewen Maclean, President, British College of Obstetricians and Gynaecologists ; Dr. Robert Hutchison, President, Royal Society of Medicine ; Dr. S. Watson Smith, Past President, British Medical Association; Dr. H. G. Dain, Deputy Chairman, Representative Body; Mr. Bishop Harman, Treasurer ; Sir Thomas Dunhill, member of Council Dr. G. C. Anderson, Medical Secretary; Dr. N. G. Horner, Editor, British Medical Journal; and Mr. L. Ferris-Scott Financial Secretary. Many of these also were accompanied by their ladies. 